\title{
The effect of environmental parameters on contaminant uptake By a passive sampler device
}

\author{
${ }^{1}$ WANDAN, E N.; ${ }^{2}$ KOPOIN ADOUBY; ${ }^{1}$ AKISSI CHANTAL \\ ${ }^{I}$ Departement des Eaux, Forêts et Environnement, INP-HB BP 1313 Yamoussoukro \\ ${ }^{2}$ Departement Génie Chimique et Agro-Alimentaire, INP-HB BP 1313 Yamoussoulro
}

\begin{abstract}
A passive sampling device previously developed was used to assess environmental contamination. It consists of a polymeric bag filled with an organic solvent in which contaminants are preconcentrated after passively diffusing from the water column. The contents of the device were subjected to analysis without further cleanup. The effect of temperature, turbulence, ionic strength, $\mathrm{pH}$, and the presence of dissolved organic material on the partioning process were examined. The results showed that increase in temperature supply the molecules with greater energy and enables them to pass through the membrane and into the solvent. Turbulence was found to disrupt the boundary layer formed around the device as a result of concentration polarization causing irregular fluctuations in the concentration of contaminants in equilibrium with the membrane. There was no discernable correlation between the concentration of contaminants accumulated by the devices and the ionic strength of the incubation solution. There was also no discernable relationship between $\mathrm{pH}$ and contaminants uptake by the sampling devices as was expected with non polar, non-ioniseable solutes. The uptake of compounds with lower molar volumes was most susceptible to the presence oh humic materials. @JASEM
\end{abstract}

Much surface water has been contaminated with organic pollutants. In Côte d'Ivoire, organochlorine pesticides including DDT, dieldrin, and lindane have been found in lagoons, rivers and lakes (Wandan and Zabik, 1996). The causes of these contaminations may include point sources, leachate from agricultural applications or industrial activities. Traditionally, the level of contamination have been assessed using fish, birds (Bedford and Zabik, 1973), benthic species (Bedford et Zabik, 1973), or zooplankton (Leversee, 1983) as biomonitors. These species accumulate contaminants to a concentration many thousand times greater than that found in the environment, thus enhancing detection (Corner, 1984). The analysis of mobile organisms such as fish and birds may provide an integrated sample of the quality of the entire ecosystem. The use of sessile species such as clams and mussels provides a time-integrated sample at one location. Still, several problems are associated with the use of these organisms as environmental monitors. Considerable time, expense and effort are spent collecting the organisms. The analysis of many individuals is essential due to the large degree of variation within the population. The interferences from endogenous biological material require that extensive cleanup techniques be used (Veith et al., 1975). To avoid the problems associated with biomonitors, direct water sampling has been employed to assess water quality. Substantial logistical and analytical problems are associated with obtaining representative water samples. The low concentration of the analyte often necessitates using preconcentration procedures or batch sampling to surpass detection limits. Data derived from batch sampling procedures may be of limited value because they represent the instantaneous concentration of the analyte at a single location (Hertz and Suffet, 1980). Thus, conventional water sampling techniques may have limited use in contaminant surveillance. On-site continuous extractors that provide time-integrated samples of large volumes of water have been used but background contamination of the adsorbent, system clogging, and limited application at remote sites due to the necessity of a power source to drive the sample and reagent pumps remain a problem.

Passive water sampling devices provide a more reliable alternative to the determination of water quality. These devices are easily deployed at remote sites as a power source is not required. Their lack of moving parts improves reliability. This technique is attractive because of its extreme simplicity; however, biofouling and a slow equilibrium rate between the polymer film and the water column limit its application as a long-term integrated sampler (Black et al., 1982). Analysis of the contents of the bags was simpler and the devices could be used where conventional biomonitors could not. Thus, passive water sampling devices display great potential as environmental monitors. This study is a series of experiments that was conducted to ascertain the effects of external parameters on the uptake efficiency of several contaminants into the polypropylene/2,2,4-trimethylpentane sampling devices. The parameters investigated included temperature, turbulence, ionic strength, $\mathrm{pH}$ and the presence of humic materials in the incubation system.

\section{MATERIALS AND METHODS}

Materials

Glass miniature sampling devices have dimensions of $5.9 \mathrm{~cm}$ by $2.0 \mathrm{~cm}$ as illustrated by fig 1 . Polymeric membranes (polypropylene) were fastened to the bottom of the miniature sampling devices with silicone glue. Ten $\mathrm{ml}$ of solvent (trimethylpentane) were added to the interior compartment. An $8 \mathrm{~mm}$ internal diameter septum sealed the top of the tube

*Corresponding author. E-mail 
and allowed easy withdrawal of samples. The area of the membrane affixed to the bottom of the device was $0.603 \mathrm{~cm}^{2}$. The samplers were suspended from a polycarbonate lid using stoppers and were allowed to equilibrate for 13 days in the exposure systems (Fig 2 ). The flowing exposure system used for the exposure of the sampling device (Fig 2) consisted of 10-L glass tank. The system was stirred with a
Tallboy's stirrer. Two Beckman pumps, pumping at $1.5 \mathrm{ml} / \mathrm{min}$., were used to pump the water solution into the incubation tank. A forma Scientifique model 2132 water bath was used to maintain constant temperature when needed.

Fig. 1: The miniature-Sampling Devices

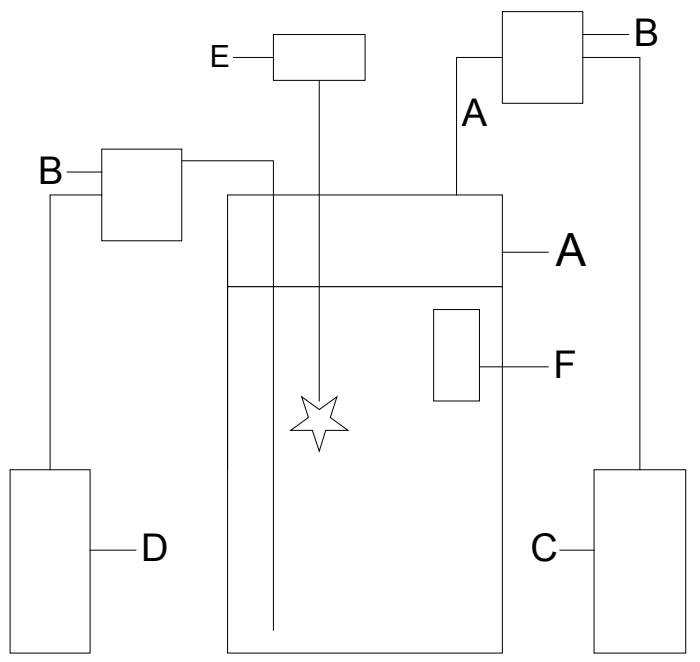

Fig. 2: Apparatus for Exposing the Miniature Sampling Devices to Aqueous Solutions of Test Compounds in a Flowing Stream. A-exposure tank, B-water pumps, $\mathrm{C}$-aqueous solution containing test compounds, D-waste container, E-precision controlled stirrer, F-sampler being tested. 
Temperature: The temperature of the circulating water bath was varied from 15 to $25^{\circ} \mathrm{C}$ in increments of $5^{\circ}$. This range represented reasonable environmental temperatures. To establish the maximum time required to reach equilibrium at $15^{\circ} \mathrm{C}$, contaminant concentrations in the polypropylene/2,2,4-trimethylpentane sampling devices were monitored at various time increments including $0.25,0.5,1,2,4,6,8,10$ days. For the studies at 20 and $25^{\circ} \mathrm{C}$, the samplers were allowed to equilibrate with their surroundings for four days before their contents were analyzed. Quadruplet samples were analyzed as described below. Whenever the temperature of the circulating water bath was altered, the system was allowed to equilibrate at the increased temperature for 24 hours before the miniature sampling devices were added.

Turbulence: The turbulence was varied by altering the number of revolutions per minute (rpm) of a Talboy's model 101 stirrer from $0,30,45$, to $60 \mathrm{rpm}$. The temperature was maintained at $20^{\circ} \mathrm{C}$ for all turbulence studies. Sampling devices were allowed to equilibrate for four days before the samples were taken.

Ionic strength: A $3.765 \mathrm{M}$ solution of sodium chloride was prepared and added to the pesticide incubation mixtures in the following quantities: 10 $\mathrm{ml}, 100 \mathrm{ml}$, and 1,000 $\mathrm{ml}$. Distilled water was added to maintain a constant volume of $37 \mathrm{~L}$. The calculated ionic strengths were $1.017 \times 10^{-1}, 1.017 \times 10^{-2}$ and $1.017 \times 10^{-3}$, respectively. The solutions were allowed to attain $20^{\circ} \mathrm{C}$ before being added to the incubation chamber. The stirring rate was maintained at $30 \mathrm{rpm}$. The sampling devices were allowed to equilibrate for four days before the samples were taken.

$p H$ : Solutions of $\mathrm{HCl}, \mathrm{NaCl}$ and $\mathrm{NaOH}$ were made in a concentration of $0.1 \mathrm{M}$. The $\mathrm{pH}$ of the incubation solutions was adjusted to $6.37,7.26$, and 8.48 by the addition of either $\mathrm{HCl}$ or $\mathrm{NaOH}$. $\mathrm{NaCl}$ was added to maintain constant ionic strength. The solution was filtered through a glass microfiber membrane, bottled and stored at $5^{\circ} \mathrm{C}$. The remainder of the procedure was performed as previously described. The $\mathrm{pH}$ after the experiment was 5.80, 6.66, and 7.58.

Humic materials: Water containing humic materials was collected from the lakes of Kossou and Ayamé and the Comoé River near the city of Ono (Côte d'Ivoire). All the water was stored at $5^{\circ} \mathrm{C}$. Three batches of solution were prepared, each with a total volume of $27 \mathrm{~L}$. Each contained water from three water bodies. Ten litre of distilled water were added to achieve sufficient volume in the incubation system. The water was spiked with the organochlorine compounds and the $\mathrm{pH}$ was adjusted to $6.25,7.80$ and 8.48. Sodium chloride was added to maintain a constant ionic strength. The water was filtered to remove any precipitating humic materials, bottled and stored at $5^{\circ} \mathrm{C}$. The remainder of the procedure was performed as previously outlined.

ANALYSIS: Pesticides accumulated by the passive sampling devices were analyzed using a PerkinElmer 8500 gas chromatograph containing an open tubular column (0.25 mm i.d., $60 \mathrm{~m}$ length) with DB1 stationary phase ( $\mathrm{J} \& \mathrm{~W}$ Scientific, Folsom, CA) and an electron capture detector. No clean up or preconcentration techniques were performed on any of the samples.

\section{RESULTS AND DISCUSSION}

Temperature: Increases in temperature enhance contaminant uptake by the sampler. As illustrated in fig 3, there is a linear relationship between the equilibrium concentration in the sampling devices and temperature. Table 10 summarizes linear regression of these data. The correlation coefficient (r) is greater than 0.99 for all the compounds studied except DDE.

Table 1: Linear Regression Data for the Relationship the Equilibrium Concentrations of Organochlorine Compounds and Temperature

\begin{tabular}{llll}
\hline Composé & b & m & r \\
\hline Lindane & 41,70 & 2,0 & 0,9983 \\
Aldrine & 57,70 & 2,9 & 0,9904 \\
Dieldrine & $-57,0$ & 6,1 & 0,9901 \\
DDE & 29,0 & 0,8 & 0,7559 \\
Methoxychlor & 1,30 & 6,8 & 0,9930 \\
\hline
\end{tabular}

Eboua N. WANDAN ${ }^{l}$; Adouby KOPOIN ${ }^{2}$; Chantal AKISS 
When we compare the slopes of these lines with the inverse of the LeBas molar volume as shown in fig 4, it is apparent that as temperature is increased, larger molecules exhibit a greater change in mobility. Larger molecules may face greater restrictions negotiating passage through the membrane material. The added energy allows them to initiate greater flexibility in the membrane. Lindane is the only molecule not following this trend and is also the only monocyclic compound in this study. Increases in temperature supply the molecules with greater energy and enables them to pass through the membrane and into the solvent.

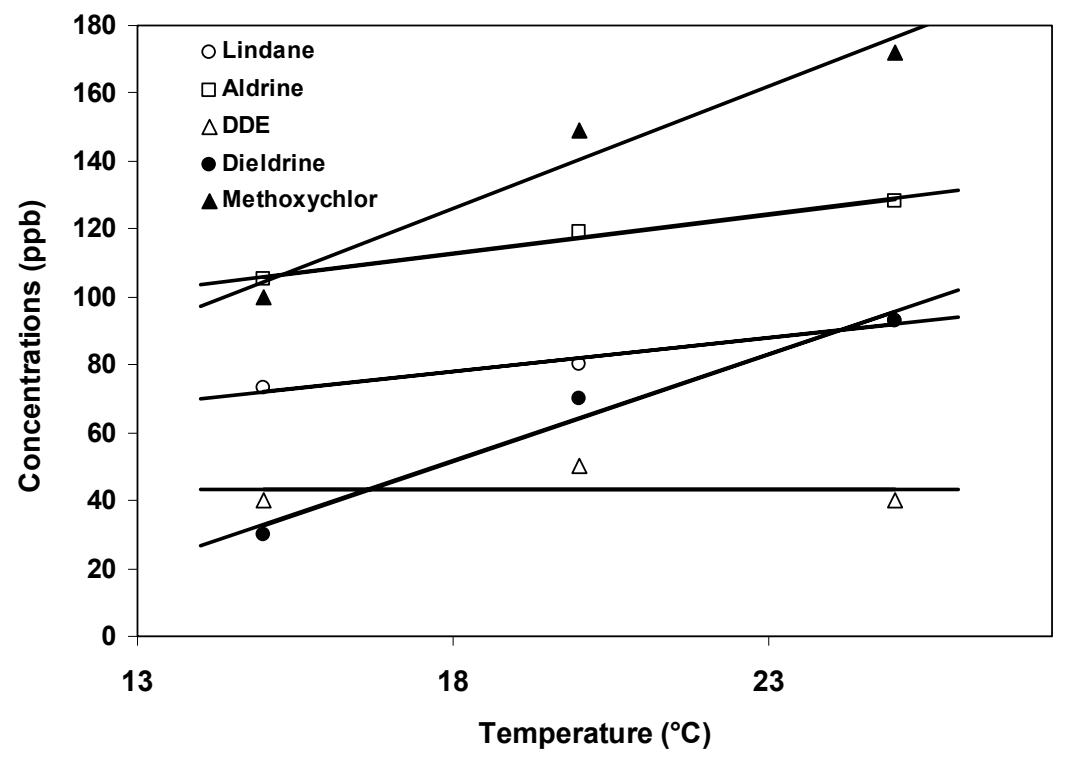

Fig 3: Contaminant Uptake as a Function of Temperature using polyprpylene/2,2,4-Trimethylpentane Miniature Sampling Devices. The devices were exposed for 4 days and the incubation chamber was stirred at n

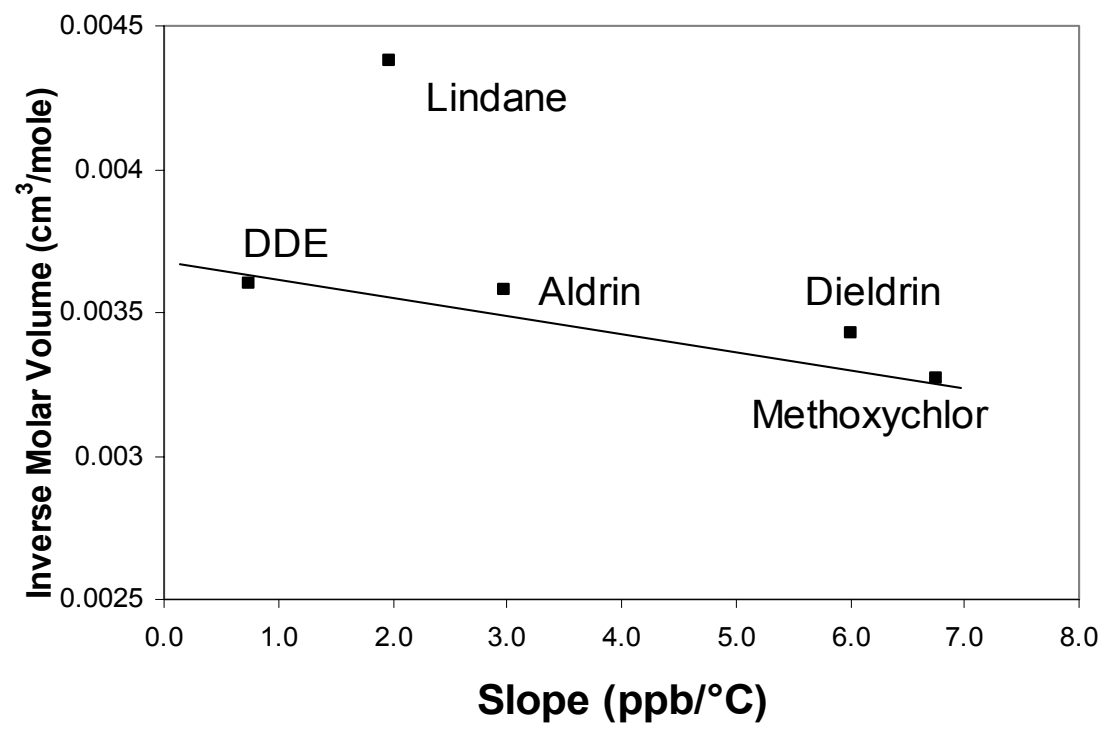

Fig 4: Temperature Dependant Change in Contaminant Uptake as a Function of the Inverse Molar Volume 
Turbulence: Fig 5 illustrates the rise in the contaminant concentration as the stirring rate is increased. The marked upswing in contaminant accumulation after approximately $45 \mathrm{rpm}$ suggests that there is sufficient turbulence to disrupt the boundary layer formed as a result of concentration polarization. This could pose a problem in environmental studies; wave action may cause irregular fluctuations in the concentration of contaminants in equilibrium with the membrane.

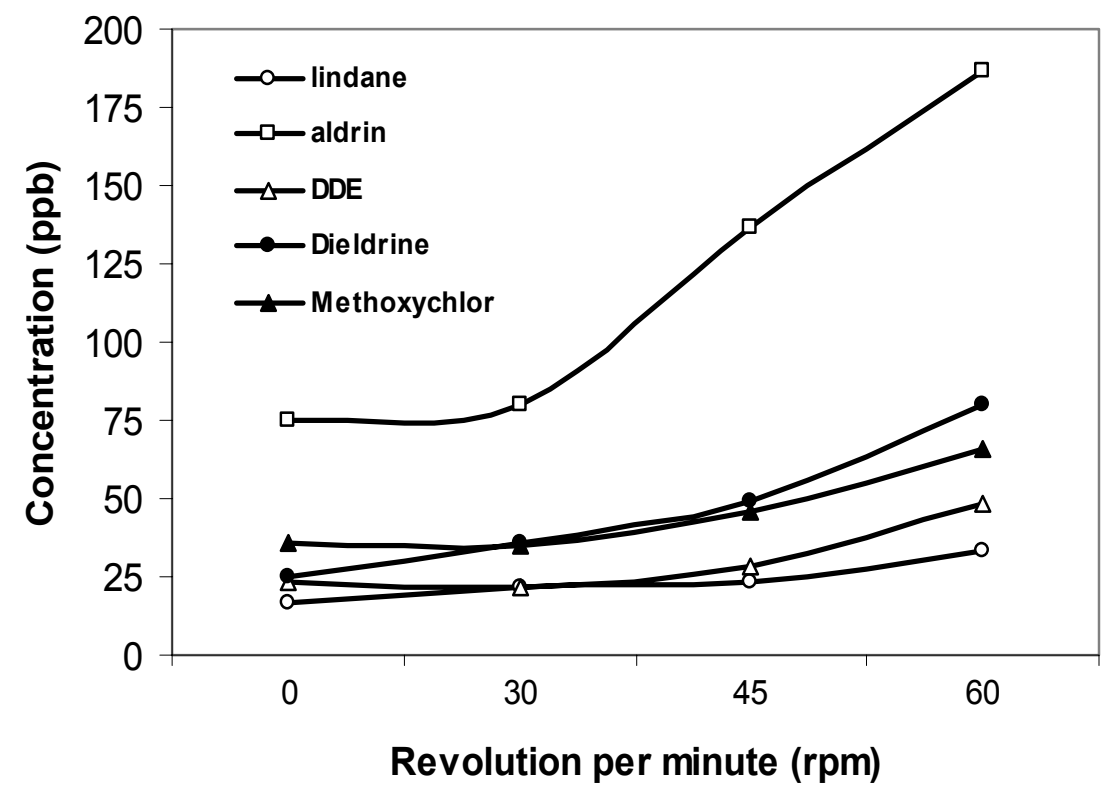

Fig 5: Effect of Turbulence on Contaminant Uptake by Polypropylene/2,2,4trimethylpentane Miniature Sampling Devices at $20^{\circ} \mathrm{C}$.

Ionic strength: Fig 6 shows that there was no discernible correlation between the concentration of organochlorine compounds accumulated by the devices and the ionic strength of the incubation solution. Increases in the ionic strength in the aqueous phase should enhance contaminant uptake because of the increased chemical potential in the water. An increased transfer of tetrachlorobiphenyl from the aqueous to vapor phase was observed as salinity was increased (Jota, 1984). Similarly it was found that the addition of electrolytes to an aqueous solution decreased the solubility of nonpolar compounds (Tulp et al., 1978). However, when a polycarbonate film was used, no differences between solute transfer in the control sample and one with an elevated ionic strength $\left(8 \times 10^{-3} \cdot \mathrm{M} \mathrm{NaCl}\right)$ were noted. Therefore, the sampling devices may prove useful in geochemical applications, especially those that involve monitoring hydrocarbon residues in brine solutions.
Figure 6 show that there was no discernible correlation between the concentration of organochlorine compounds accumulated by the devices and the ionic strength of the incubation solution. Increases in the ionic strength in the aqueous phase should enhance contaminant uptake because of the increased chemical potential in the water. An increased transfer of tetrachlorobiphenyl from the aqueous to vapor phase was observed as salinity was increased (Jota, 1984). Similarly it was found that the addition of electrolytes to an aqueous solution decreased the solubility of nonpolar compounds (Tulp et al., 1978). However, when a polycarbonate film was used, no differences between solute transfer in the control sample and one with an elevated ionic strength $\left(8 \times 10^{-3} . \mathrm{M} \mathrm{NaCl}\right)$ were noted. Therefore, the sampling devices may prove useful in geochemical applications, especially those that involve monitoring hydrocarbon residues in brine solutions.

$\mathrm{pH}$. There is no discernible relationship, but this is to be expected with non polar, non- ionizeable solutes. Blanchard and Hardy also performed experiments to 
examine the effect altering the $\mathrm{pH}$ from 3.0 to 8.0 has on the membrane penetration by solutes, and found no relationship. This study was necessary to provide blank samples for the humics experiment.

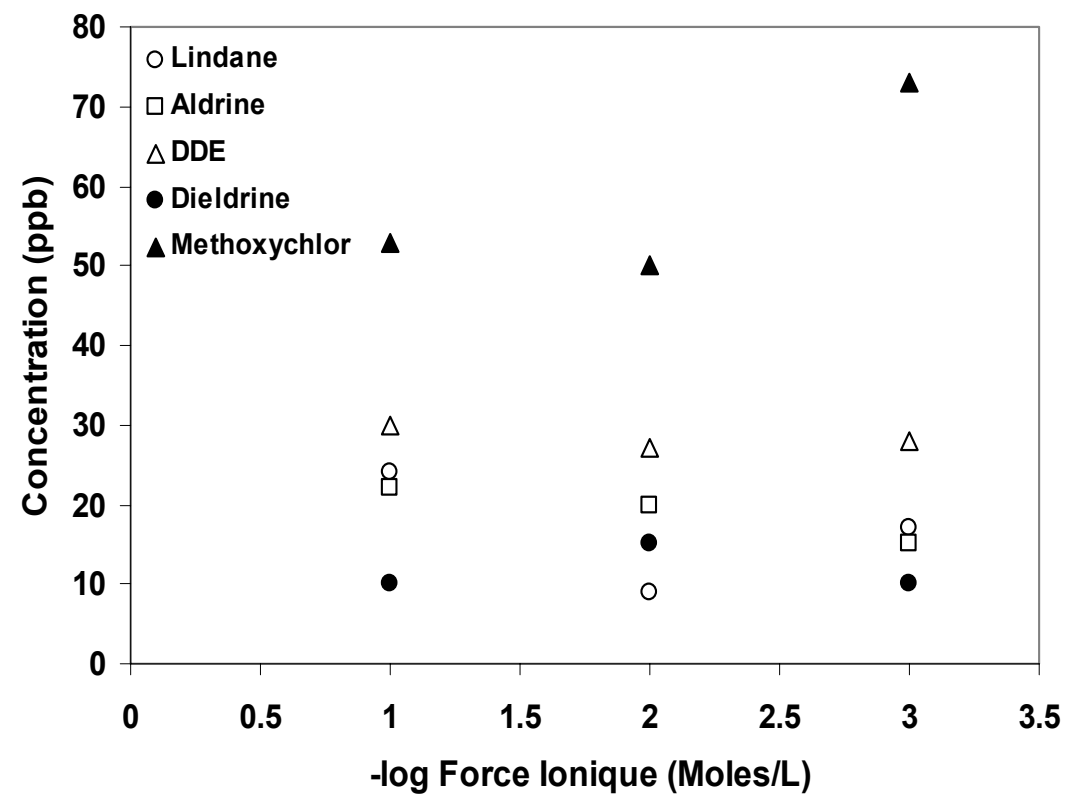

Fig 6: Uptake of Various Contaminants by Polypropylene/Trimethylpentane Miniature Sampling Devices as a Function of Ionic Strength. The temperature was maintained at $20^{\circ} \mathrm{C}$ and the incubation chamber was stirred at $30 \mathrm{rpm}$.

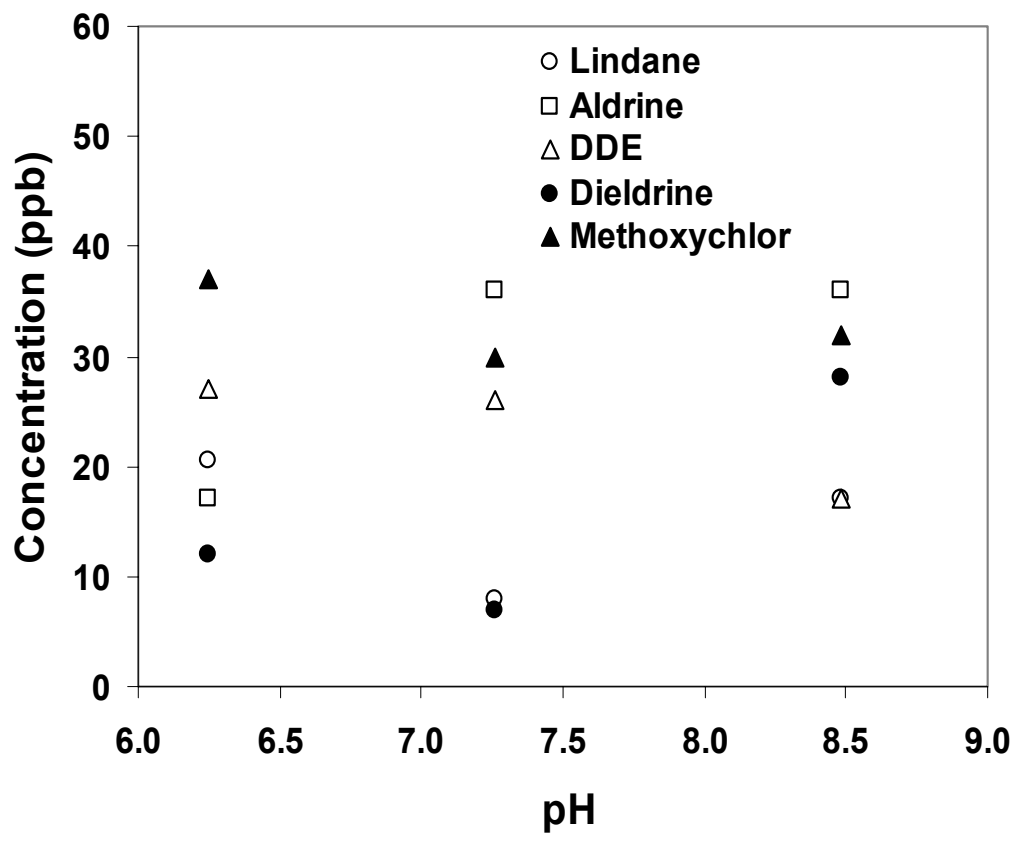

Fig 7: Uptake of Various Contaminants by Polypropylene/Trimethylpentane Miniature Sampling Devices as a Function of $\mathrm{pH}$. The temperature was

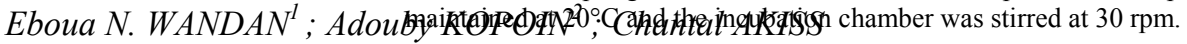


Humic Materials: The pigmentation of natural waters is caused by a class of dissolved substances, called humics, which are by-products of plant decomposition. Their precise chemical structure is unknown, but it has been estimated that $20-30 \%$ of the carbon atoms in humic materials are aromatic. The skeleton of humic materials consists largely of hydrocarbon molecules, but carboxyl, phenolic and methoxy functional groups are also present. Nitrogen atoms also may exist in the molecules (1-2\%). The molecular weight of humic materials ranges from 800 to $250,000 \mathrm{~g} / \mathrm{mole}$ (Beckett et al., 1987). Humic substances play a role in the transport and fate of xenobiotics in the environment. These substances also interact with nonpolar organic compounds such as petroleum hydrocarbons, 2,4,5-T, benzo(a)pyrene, phenanthrene, anthracene, DDT, phthalate esters and alkanes decreasing their bioavailability (Beckettet al., 1987 ; Wershaw et al., 1979 ; Hasset and Anderson, 1979 ; Anderson, 1982 ; Leversee et al., 1983).

Fig 8 illustrates the uptake of contaminants by propylene/2,2,4-trimethylpentane miniature sampling devices that were exposed to a humic-laden incubation solution as a function of $\mathrm{pH}$. There is no clear relationship between alterations in $\mathrm{pH}$ and contaminant uptake by the sampling devices. These results were compared to the concentration of organochlorine compounds accumulated by the devices when humic materials are absent from the incubating chamber in figures 9 to 12 .

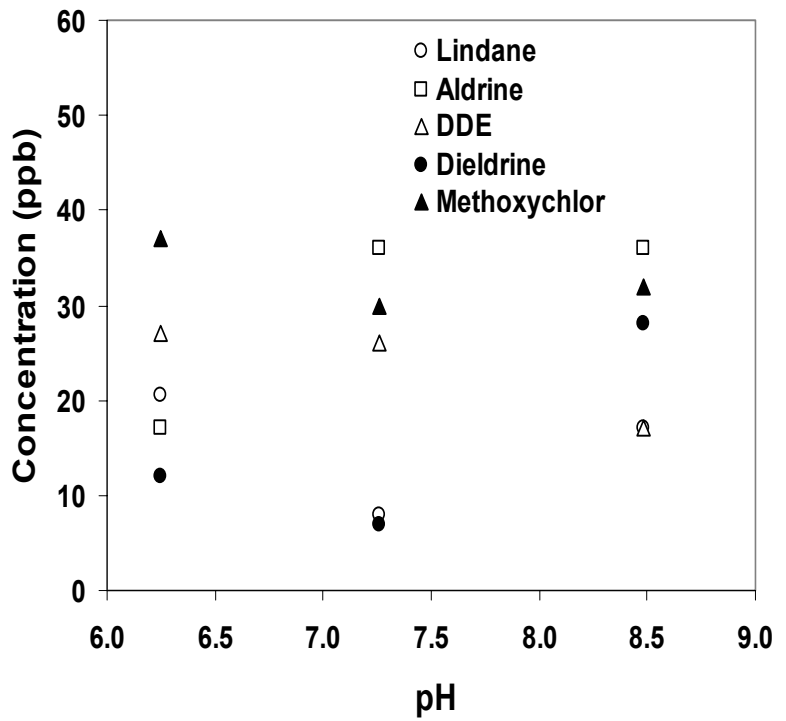

Fig 9: Uptake of various contaminants by Polypropylene/2,2,4-Trimethylpentane Sampling Devices at $\mathrm{pH} 7$ with and without Humic Materials. The temperature was maintained at $20^{\circ} \mathrm{C}$ and the incubation chamber was stirred at 30rpm.

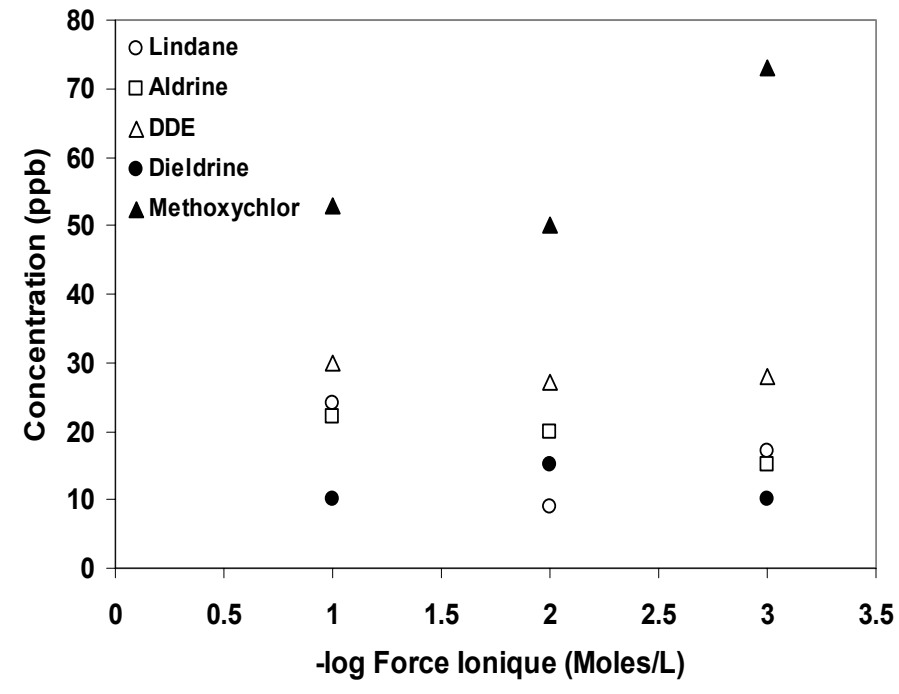

Fig. 8. Uptake of various contaminants by polypropylene/trimethlpentane mixture sampling devioces exposed to humic materials as a function of $\mathrm{pH}$. The temperature was maintaned at $20 \mathrm{oC}$ and the incubation chamber was stirred at $30 \mathrm{rpm}$

At neutral $\mathrm{pH}$, the uptake of lindane and dieldrin wolsime. Dieldrin may be interacting with the humic materials markedly decreased by the presence of humic materials, whidethe epoxy oxygen atom.

the accumulation of methoxychlor remained the same. The partitioning of remaining compounds, aIdrin and DDE itoa $\mathrm{pH}$ of 8, the elevated levels of humic and fulvic the miniature sampling devices was slightly decreased. At thaserials decreased contaminant levels in the sampling $\mathrm{pH}$, some binding to humic acid should be occurring. Ttreices. The most pronounced reduction in solute marked decrease in uptake of lindane by the sampling devacesumulation was observed for lindane. The binding of this may be due to a size or shape specific interaction as lindancoispound to humic and fulvic substances may be enhanced the only mono-cyclic compound studied and has lowest mdire to its reduced molar volume. Likewise, lindane and 
by the devices and have the largest molar volumes. Thohowed similar changes in uptake. remaining compounds that have similar molar volumes

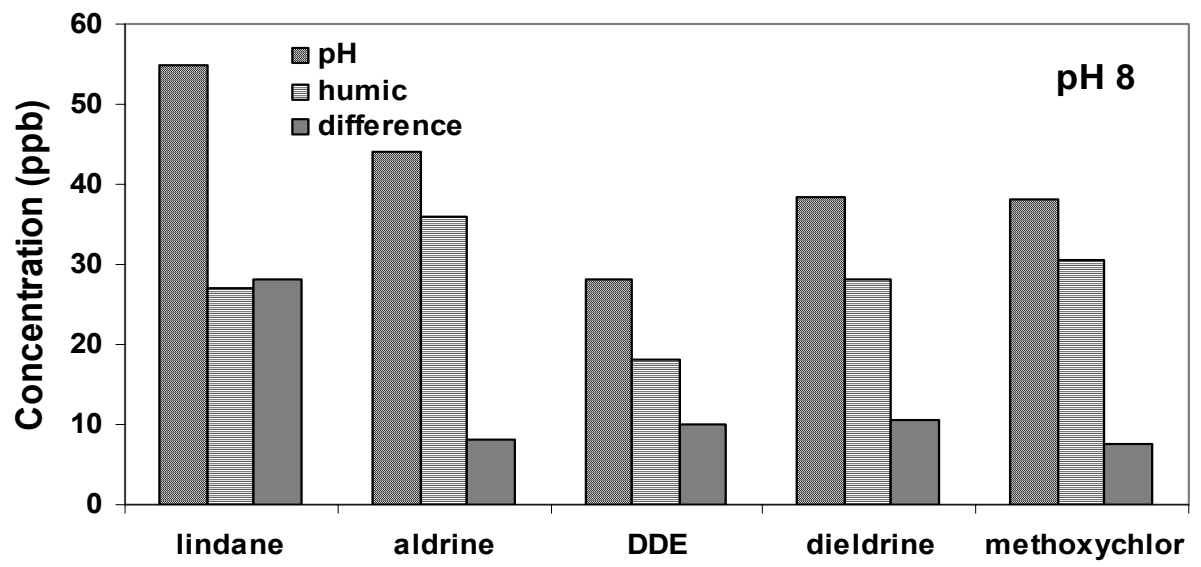

Fig 10: Uptake of various contaminants by Polypropylene/2,2,4-Trimethylpentane Sampling Devices at $\mathrm{pH} 8$ with and without Humic Materials. The temperature was maintained at $20^{\circ} \mathrm{C}$ and the incubation chamber was stirred at $30 \mathrm{rpm}$.

At a $\mathrm{pH}$ of 6, the greatest decreases in uptake occurred for aldrin and dieldrin. This suggests that the shape of these These results may be due to differences between naturally molecules is more compatible with binding to fulvic acid.occurring humics and those purchased from Aldrich. Lindane uptake into the devices is also markedly limited Other studies found that as the $\mathrm{pH}$ was decreased, humic and may be due to a size specific interaction with fulvic acids became more hydrophobic and the cationic sites acids. Blanchard and Hardy (1986) added Aldrich ${ }^{\mathrm{R}}$ humic were no longer charged. There was an increase of binding acid to their solution at a concentration of $2500 \mathrm{ppm}$ and to hydrophobic compounds which resulted in a limiting found no change in membrane passage. transfer from the aqueous Phase (Jota, 1984; Carter and Suffet, 1982). The uptake of compounds with the lower molar volumes is most susceptible to the presence of humic materials, this is due to the humic and fulvic micellular site and the contaminants' ability to enter the hydrophobic centre of the micelle.

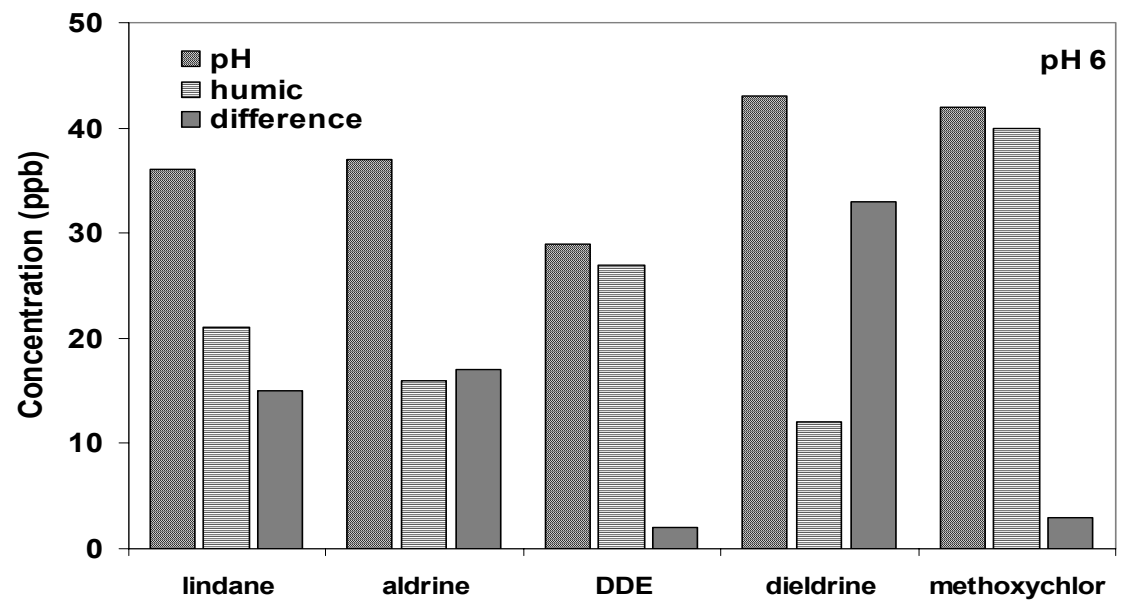

Fig 11: Uptake of various contaminants by Polypropylene/2,2,4-Trimethylpentane Sampling devices at $\mathrm{pH} 6$ with and without Humic materials. The temperature maintained at $20^{\circ} \mathrm{C}$ and the incubation chamber was stirred at 30rpm.

Eboua N. WANDAN ${ }^{1}$; Adouby KOPOIN ${ }^{2}$; Chantal AKISS 
Conclusion: Uptake of organochlorine compounds by the water sampling devices is influenced by temperature, turbulence, and the presence of humic materials. Ionic strength and $\mathrm{pH}$ did not affect this partitioning process.

Larger molecules were most affected by increasesHaissett, J.P; Anderson, M.A (1979). Effect of temperature; the added energy enhancing membrane pass gissolved Organic Matter on Adsorption of Although increases in temperature promote contamimandrophobic Organic Compound by River and accumulation, the temperature in large bodies of water not change rapidly over the course of a biomonitofinghnol., 13, 1526-1529.

experiment. Therefore, contaminant uptake in field studies

should not be greatly affected by temperature changlestz, C.D; Suffet, I.H (1980). "Detection of Organic Turbulence-limited concentration polarization and enhanCadcinogen in Drinking Water: A Review of contaminant accumulation. Although, turbulence experienCodcentratio/Isolation Methods" in Organic in natural waters is to have a similar effect on the sampliagcinogens in Drinking Water Detection, Treatment, devices, biomonitors are also susceptible. Exposure to huanid Risk Assessment. RAM, Calabrese and materials decreased contaminant uptake in the devices as Vithistman eds., Willey and Sons: New York, 95-130 biomonitors. Further studies should investigate the impact of

these environmental parameters in field applications.

\section{REFERENCES}

Beckett, R; Jue, Z; Giddings, J.C (1987).

Distributions of Fulvic and Humic Acids Using Flow

Field-Flow Fractionation. Environ. Sci. Technol., 21, 289-295.

Bedford, J.W; Roelofs, E.W; Zabik, MJ (1968). The freshwater mussel as a biological monitor of pesticide concentration in a lotic environment. Limn. Ocean., v. $13: 118-126$.

Bedford, J.W; Zabik, M..J (1973). Bioactive compounds in the aquatic environment: uptake and loss of DDT and dieldrin by freshwater mussles. Arch. Environ. Contam. And Toxicol. 1(2), 97-111
Jota, M.A.T (1984). Effects of Environemental Parameters on the binding interaction Between Tetrachlorobiphenyl and dissolved Humic Materials. M.S. Thesis, S.U.NY. College of Environemental Science and Forestry, Syracuse, NY.

Leversee, G.J; Landrum, P.F; Giesy, J.P; Fannin, T, (1983). Humic Acids Reduce Bioaccumulation of Some Polycyclic Aromatic Hydrocarbons. Can. J. Fish. Aquat. Sci., 40 (Suppl. 2), 63-69.

Tulp, M.Th; Schmitz, M.R; Hutzinger, O (1978). The bacterial metabolism of 4,4'-dichlorobiphenyl, and its suppression by alternative carbon source.

Chemosphère, 10, 849-860.

Veith, G.D; Kuehl, D.W; Rosenthal, J (1975).

Preparative method for gas chromatographic/mass

Blanchard, R; Hardy, J.K (1986). Automated Permeation spectral analysis of trace quantities of pesticides in Sampler for Volatile Priority Pollutants. Anal. Chem., 58, fish tissue. J. Assoc Off Anal Chem. Jan;58(1):1-5 1529.

Carter, C.W; Suffet, I.H (1982). Binding of DDT to dissolved humic materials. Environ. Sci. Technol., $16,735-740$.

Hassett, J.P; Anderson, M.A (1982). Effect of Dissolved Organic Matter on Adsorption of Hydrophobic Organic Cpmpound by River and Sewage Borne Particulate Matter. Water Res., 16, 681-686.
Wershaw, R.L; Burcar, P; Goldberg, M.C, (1969). Interaction of Pesticides with Natural Organic Material. Environ. Sci. Technol. 3:271-273.

Wandan, E.N; Zabik, M.J (1996). Assessment of the contamination of surface water and fish from Côte d'Ivoire. J. Environ. Sci Health, B31(2), 225-240. 